\title{
Effects of Duration and Contents of Mindfulness Training on Depression*
}

\author{
Qiong Wu, Lin Shi, Zhipeng Xia, Lida Lu \\ Beijing Key Laboratory of Applied Experimental Psychology, School of Psychology, \\ Beijing Normal University, Beijing, China \\ Email: wuqiongpsychology@163.com
}

Received March 16 ${ }^{\text {th }}, 2013$; revised April 20 ${ }^{\text {th }}, 2013$; accepted May $18^{\text {th }}, 2013$

Copyright (C) 2013 Qiong Wu et al. This is an open access article distributed under the Creative Commons Attribution License, which permits unrestricted use, distribution, and reproduction in any medium, provided the original work is properly cited.

\begin{abstract}
This study aimed to find a simple and effective mindfulness training method for intervening depression. 95 university students with moderate or severe depression participated in the study and they were divided into three mindfulness training groups: 8-week complete group, 8-week informal group, and 4-week group. All subjects completed Beck Depression Inventory (BDI- II) and Five Fact Mindfulness Questionnaire (FFMQ) before the intervention, after which, 55 subjects completed the assessments once more. Results showed the scores of specific dimensions representing mindfulness levels were different. For the 4-week group, scores of description, action aware and nonjudge significantly were improved, while the other two groups were improved significantly on all the five dimensions, especially the informal training group. In the discussion, it focused more on the effects of training time and training contents, and briefly discussed the relation of subjects dropout, subjects attendance, homework completion status and intervention effects. In conclusion, all the three intervention modes have magnificent intervention effects. Integrated many sided, 8-week informal training is of the best effects, which may be considered as a better mindfulness training mode henceforth, however, the comparison between the formal training and informal training still needs further study.
\end{abstract}

Keywords: Mindfulness; Depression; Intervention; Mindfulness-Based Cognitive Therapy

\section{Introduction}

\section{The Origin of Mindfulness Training}

Mindfulness, sati in Pali Language, which originated from Southern Buddhism, is an important mode of meditation (Shaw, 2006: pp. 19, 76). In 1970s, Jon Kabat-Zinn created effective Mindfulness-Based Stress Reduction (MBSR), which was based on his solid specialty foundation and absorbed the nutrition and essence of meditation in the East. Kabat-Zinn defined mindfulness as "paying attention in a particular way: on purpose, in the present moment, and nonjudgmentally" (Kabat-Zinn, 1994). Meanwhile, he also emphasizes that mindfulness training is only to pay attention to observing the current internal and external experience, emotions or behaviors, while it is not to respond to them immediately. Thus, the practice of mindfulness skills could lead to the ability to experience pain sensations without excessive emotional reactivity (Baer, 2006).

Since Kabat-Zinn published the first clinical research report on Mindfulness-Based Stress Reduction and Chronic Pain in 1982, the mindfulness training course has gradually be widely recognized in the USA, and many psychotherapy methods, which take mindfulness training as core technology or is based on mindfulness training, have been developed (Tan \& Wu, 2009), such as Mindfulness-Based Cognitive Therapy (MBCT),

"A Joint-Project for Beijing City Board of education (SYS100270661).
Dialectical Behavior Therapy (DBT) and Acceptance and Commitment Therapy (ACT).

Mindfulness-Based Cognitive Therapy (MBCT) is a therapy to prevent recurrence of depression that was developed and worked out by Teasdale, Segal and William in 1995 by combining Mindfulness-Based Stress Reduction (MBSR) and Cognitive Therapy. The core skill that MBCT teaches us is that: by awareness training, the participants realize ubiquity of "Psychological operation mode", namely, individuals' habitual, unconscious and self-driven reaction mode towards thought, inner feeling and somatesthesia. And practice to be released from such psychological state and then convert into "existing mode", that is, to learn to accept and admit all current objective experience, while it does not need to respond to and change such negative experience (Deng, 2009).

\section{Application and Research of Mindfulness Training}

So far, mindfulness training has been separated from the understanding perspective of religious belief, has become one of the important methods in psychotherapy field, and has been widely used in multiple clinical treatment and practical research. Besides, cognitive psychology field has also begun to pay attention to research of neural mechanism of mindfulness and to the change of individuals' cognitive system brought by mindfulness training.

More and more empirical study demonstrates that MBSR and 
MBCT have good therapeutic effect on different groups and different diseases. Since Jon Kabat-Zinn established stress reduction clinic to provide MBSR, he and his colleagues have helped over 10,000 patients with different diseases, including heart disease, cancer, Aids, chronic pain, gastrointestinal tract problems caused by excessive pressure, headache, high blood pressure, sleep disturbance, anxiety and panic. MBSR can also be used to treat working pressure and job burnout of nursing personnel (Cohen-Katz, Wiley, Capuano, Baker, \& Shapiro, 2004, 2005a, 2005b), mental distress and fatigue of those suffering from rheumatic arthritis (Zangi et al., 2012), pressure and anxiety of those suffering from breast cancer (Anna, Yvonne, \& Catherine, 2004), and dyspareunia problem of females that suffered from sexual abuse in their childhood (Brotto, Seal, \& Rellini, 2012); and it is helpful for the response of patients suffering from rheumatoid arthritis towards chronic pain and depressive state, and enhance quality of life (Zautra et al., 2008), and helpful for teenagers to reduce anxiety, depression and pain symptoms and enhance self-esteem and sleep quality (Biegel, Brown, Shapiro, \& Schubert, 2009; see also Rood, Roelofs, Bogels, \& Alloy, 2010). Mindfulness training can improve eating pattern and adjust Cortisol Awakening Response (CAR), and it may reduce abdominal adipose tissue as time goes on ((Daubenmier et al., 2011). In relative to MBSR, MBCT can obviously reduce the depression recurrence risk of patients that have suffered from depressive episodes for three or more times. For patients that have suffered from recurrence of depression for three or more times, MBCT can bring the recurrence rate from $78 \%$ to $36 \%$. Moreover, MBCT has more effective automatic processing of cognitive emotions (Teasdale, Segal, Williams, Ridgeway, Soulsby, \& Lau, 2000; Ma \& Teasdale, 2004). MBCT is also proved to have alleviating action on depression and anxiety symptoms of patients with suicidal idea (Williams, Danielle, Catherine, Melanie, \& Fennell, 2006; see also Marchand, 2012) and patients with bipolar disorder (Williams, 2008). Other cognitive therapies based on mindfulness are widely used in treating borderline personality disorder and anxiety disorder (Segal, Williams, \& Teasdale, 2001).

However, while a large number of researchers have huge enthusiasm on mindfulness training and widely use mindfulness training, some problems occur accordingly. Although many researches use the concept of "mindfulness training", the specific mindfulness intervention modes vary greatly, which is especially obvious in cognitive study.

When Anna (2004) treated patients with breast cancer, 8week mindfulness training that was conducted once a week and 1.5 hours each time was adopted, in which three mindfulness trainings were mainly used: body scanning, meditation and yoga (hatha yaga) as well as didactic, inductive and learning the experience mode relevant to stress response (Anna, Yvonne, \& Catherine, 2004). Daubenmier and Kristeller (2011) designed a set of novel and preliminary mindfulness intervention mode according to MBSR, MBCT and MB-EAT (Mindfulness-Based Eating Awareness Training), and conducted intervention for 57 fat women (average body mass index $(\mathrm{BMI})=31.2$ ). Mainly body scanning, meditation, yoga and three minutes breathing space practice were conducted, the subjects conducted a 2.5 hour group activity once each week, and they practiced mindfulness before having meals besides doing 30-minute homework. The cortisol awakening response of subjects had been obviously reduced and their weights had stopped increasing.
The mindfulness training adopted by Deng Yuqin (2009) referred to the curriculum design of MBCT and MBSR. The participants attended the mindfulness training course collectively once a week, which lasted for 8 weeks with 1.5 - 2 hours each time. After the intervention, participants were obviously improved in symptom distress, social role performance, interpersonal relationship and life quality in effect evaluation scale. Shi Zhenyan (2011) used mindfulness intervention that lasted for 4 weeks with half a day for each time. After intervention, university students had positively improved their anxiety level, and the maintenance effects were good.

Hoelzel and Carmody (2010) adopted 8-week MBSR training mode, with one group activity every week which lasted for 2.5 hours and practice was conducted once in the six week which lasted 6.5 hours. It is found that the grey substances in the hippocampus on the left side of the practicers was increased, which were relevant to learning and memory processing, mood adjustment, self-reference processing and thinking ability. Tang (2007) used short-time mindfulness meditation training in the research, the experimental group received 20-minute comprehensive meditation training (including mindfulness meditation) for 5 days, with the results that the training could enhance attention and self-control ability, and the scores of anxiety, depression and anger had been decreased obviously; Vigour in Profile of Mood States Scale is higher; cortisol related to pressure has been obviously reduced; immunological competence has been increased (see also Chambers, Lo, Yee, \& Allen, 2008). Chambers (2008) guided 20 participants to have a 10-day centralized mindfulness meditation training, which showed that it obviously enhanced working memory performance and continuous attention of participants. Ortner, Kilner and Zelazo (2007) found that 7 -week mindfulness meditation training could reduce the emotional interference (especially negative emotional interference) in cognitive tasks, so that individuals could focus on cognitive tasks. Zeidan (2010) used simplified mindfulness meditation training in the research, and after 4-day training, participants' visual space processing, working memory and executive capability had been strengthened, and sustained attention had been obviously enhanced. In the research of Semple (2010), the participants received 4-week mindfulness practice with frequency of twice a week, and they practiced twice every day after going home, while the control group only conducted muscle relaxation training. After 4 weeks, compared with control group, the mindfulness group had higher discriminability in signal detection tasks, and had obvious improvement in tasks required continuous attention, but the two groups had no obvious difference in performance of the two tasks of concentricity and restraining distractions. Lutz (2008) considered that meditation could be divided into two types, namely focused attention meditation and open monitoring meditation. After practice of the first type of meditation, it will cause nervous physiology changes, which are demonstrated in: continuity of attention, such as improvement of test performance in continuous tasks and binocular rivalry tasks; selectivity of attention, such as improvement of test performance in Posner clue tasks. And some researchers use only 12-minute practice with attention to breathing in the mindfulness research (Alberts \& Thewissen, 2011).

\section{Problems Raised}

To sum up, although a lot of research has demonstrated in- 
tervention effects of mindfulness training in many aspects, mindfulness training modes adopted in the research are various, and the training arrangements have no longer been standard MBSR and MBCT modes. In the training contents, researchers tend to use simple meditation training to replace mindfulness training in various forms; in time arrangement, researchers tend to shorten training time, some research arranges 8-week group training with once each week, some research arranges 4-week training with twice each week, and some research arranges 10day or 5-day short-term training. And for MBSR method, some research only has centralized training and does not require practice at home, while some research has some task practiced at home.

There are many methods for mindfulness training, and some requires longer time, such as body scanning which lasts about 40 minutes; some mindfulness training method can be conducted in daily life and some participants do not need specially arrange time for practicing. Then, what kind of training is effective? Is the effect of short-term training different from that of long-term training? Is the effect of formal training different from that of informal training? The answers to these questions are good for the application of mindfulness training.

The assumption of the research is that, if the simplified and short-term mindfulness training is proved to be effective or its difference from the standard intervention mode of MBCT is not obvious, we will be able to find a shorter-term and more effective intervention mode. Meanwhile, a set of mindfulness training operation standard that is more simplified, standardized and strictly operable can be established.

The research mainly refers to MBCT curriculum design and it re-designs the mindfulness training, which can be divided into three intervention groups, and can be divided into 8-week training and 4-week training in terms of time, and can be divided into complete training and informal training in terms of contents. Besides, it will control the group variables that might affect intervention effects. It is expected that the 8-week complete mindfulness training has the best intervention effect, and mindfulness training with simplified time or simplified content will weaken the intervention effects.

\section{Methods}

\section{Subjects}

Recruitment advertisement had been put up in many universities in Beijing, and totally 156 people apply to participate in the research, who had never contact mindfulness practice before. The followings were the standard for selecting the applicants: first, the applicants stated that they needed emotions adjustment and they were voluntary to actively participate in activities, second, their scores in Beck Depression Inventory should not be lower than 14 points. Besides, the applicants with psychotic disorder, depression and bipolar disorder should be excluded, and applicants with expression capability should be excluded. With preliminary talk and scale screening, the scores of 36 people in Beck Depression Inventory were lower than 14 points and they did not meet the selecting requirements; 6 people chose to quit after preliminary understanding the intervention modes, among which 5 people could not guarantee to participate in the group activity every week and 1 person did not want share information in the group. 19 people could not be contacted with after application. Finally, 95 participants participated in the research and sign the informed consent form.

\section{Tools}

\section{Beck Depression Inventory II (BDI-II)}

Beck Depression Inventory is one of the mostly widely-used depression symptoms self-rating scales, which is used for depression symptoms evaluation for both patients with various illness and normal people. Byrne, Stewart and Lee (2004) tested for the validity of a Chinese version of the BDI-II which was used by some Hong Kong community (i.e., nonclinical) adolescents. And also, Wang et al. (2011) assessed the reliability and validity of the Chinese version of BDI-II with depressed patients. BDI-II Chinese version includes 21 items and has good reliability and validity, with Cronbach $\alpha$ coefficient of 0.94 , correlation coefficient between different items of 0.18 0.71 , correlation coefficient between different items and the total score of BDI-II of $0.56-0.82$, and retest correlation coefficient is $0.55(p<0.05)$; the scores of BDI-II are positively correlated with Hamilton Depression Scale $(\mathrm{r}=0.67, p<0.01)$ (Wang et al., 2011). Therefore, it can be used as a self-rating tool to evaluate the seriousness of depression symptoms. Each item can be divided into four levels according to the seriousness of symptoms with scores from 0 to $3,0=$ none, $1=$ common, 2 $=$ serious, $3=$ severely serious. For example, $0=\mathrm{I}$ do not feel sad; 1 = I feel sad; 2 = I am sad all the time and I can't snap out of it; 3 = I am so sad and unhappy that I can't stand it. The total of the scores of all items are called total score, when which is between 0 to 4 , it shows none or extremely slight depression; when it is between 5 to 13 , it is slight depression; when it is between 14 to 20 , it is moderate depression; when it is 21 points or is above 21 points, it is major depression.

\section{Five Fact Mindfulness Questionnaire (FFMQ)}

Five fact mindfulness questionnaire is compiled by Baer, Smith, Hopkins, Krietemeyer and Toney (2006), they are 39 subjects and there are five items: observation items, describe items, act with awareness items, nonjudge items and nonreact items. The five fact mindfulness questionnaire is of good reliability and validity and the Cronbach $\alpha$ of each sub-scale is: 0.83 for observe items, 0.91 for describe items, 0.87 for act with awareness items, 0.87 for nonjudge items and 0.75 for nonreact items.

Five Fact Mindfulness Questionnaire (Chinese version) was compiled by Deng and Liu in 2009, and the reliability for internal consistency of 5 items of the questionnaire: 0.746 for observe items, 0.843 for describe items, 0.794 for act with awareness item, 0.659 for nonjudge item and 0.448 for nonreact item. Except for nonreact fact, the reliability of the other items in Chinese specimen is over 0.65 . The retest reliability of five facts are between 0.436 to 0.741 . In the verification fact analysis in Chinese version, IFI, TLI and CFI have reached over 0.90 , $\mathrm{Nn}$ is close to 0.90 , RMSEA is less than 0.08. In all, the reliability and validity of Chinese version of FFMQ among university students have reached psychometrics requirements (Deng, 2011).

\section{Mindfulness Training Mode}

The research adopted three mindfulness training modes: 8week complete mindfulness training, 8-week informal mindfulness training and 4-week mindfulness training. The training content was mainly based on mindfulness cognitive therapy, and the time and curriculum arrangement was adjusted in dif- 
ferent degrees. For 8-week complete mindfulness training, it was group activity with 8 -week intervention time, and all trainings in mindfulness cognitive therapy were conducted, and the items were repeated for more than once inside the group; The main differences between 8-week informal mindfulness training and formal training were that, informal mindfulness training emphasized practice in daily life mode and there was no formal long-time mindfulness body scanning each day. 8-week informal mindfulness training was the group activity with intervention time of 8 weeks, and all trainings in the mindfulness cognitive therapy excepted body scanning are conducted, the group repeated the items within the group for more than once; 4-week complete mindfulness training had intervention time of 4 weeks, and all trainings in mindfulness cognitive therapy were conducted, all items only be practiced for once in the group and refer to Figure 1 for specific curriculum arrangement.

\section{Research Process}

95 subjects received test of Beck Depression Inventory and Five Fact Mindfulness Questionnaire before entering the group, and the test scores were taken as pretest scores before intervention. There was no obvious difference between the pretest scores among three groups before intervention. Through the use of computers, 95 subjects were divided into three groups with 32 people, 32 people and 31 people respectively.

The three groups of subjects received three different mindfulness trainings respectively, and the interventions began in the same week. The interventions were focused on group activities which took place once every week with two hours each time.
Meanwhile, the subjects were required to complete homework which cost about 30 minutes every day and which cost about 40 minutes for 4-week group. For the specific arrangement of each activity, refer to Table 1 . At the end of each curriculum, the subjects would receive some reading materials and be arranged the homework. The activity venue for the three groups was the same fixed activity room with comfortable environment.

The mindfulness training for the three groups was instructed by the same instructor, who was the author of the thesis. The instructor had participated in Kabat-Zinn Mindfulness-based Stress Reduction Workshop, grasped mindfulness training skills, known the progress of mindfulness research and had practiced mindfulness for one year. Training progress in each week was supervised by a supervisor, who had been engaged in depression treatment for years and was doing relevant research in mindfulness training. Besides, a research assistant was assigned for each group.

After mindfulness training was over, the remaining subjects in the three groups were respectively 16,19 and 20 people, and the dropout rates were $50 \%, 40.6 \%$ and $38.7 \%$ respectively, and refer to Table 2 for details. The remaining 55 subjects received tests of Beck Depression Inventory and Five Fact Mindfulness Questionnaire again which were taken as posttest scores. The situations of the subjects during the intervention can be seen in Figure 2 .

\section{Results}

There is no missing data among the subjects. All data are handled with by SPSS17.0 statistical software, and the total

\begin{tabular}{|c|c|c|c|}
\hline Week & 8-week complete mindfulness group & 8-week informal mindfulness group & 4-week mindfulness group \\
\hline 1 & Introduction; Stretching; Body scan; & Introduction; Stretching; & $\begin{array}{l}\text { Introduction; Stretching; Body scan; } \\
\text { The Raisin Exercise; }\end{array}$ \\
\hline 2 & $\begin{array}{l}\text { Body scan; Breathing meditation; } \\
\text { The Raisin Exercise; }\end{array}$ & $\begin{array}{l}\text { Breathing meditation; } \\
\text { The Raisin Exercise }\end{array}$ & $\begin{array}{l}\text { Breathing meditation; } \\
\text { Walking mindfully; Breath space; }\end{array}$ \\
\hline 3 & $\begin{array}{l}\text { Breathing meditation; } \\
\text { Walking mindfully; Stretching; }\end{array}$ & $\begin{array}{l}\text { Breathing meditation; } \\
\text { Walking mindfully; Stretching; }\end{array}$ & $\begin{array}{l}\text { Sitting meditation- } 30 \text { '; Sharing the } \\
\text { links between mood and thoughts; }\end{array}$ \\
\hline 4 & $\begin{array}{l}\text { Walking mindfully; Sittingmeditation-15'; } \\
\text { Breath space-routine; }\end{array}$ & $\begin{array}{l}\text { Walking mindfully; Sitting meditation-15'; } \\
\text { Breath space-routine; }\end{array}$ & $\begin{array}{l}\text { Reading poetry; Recognizing relapse; } \\
\text { Suggestions; New start }\end{array}$ \\
\hline 5 & $\begin{array}{l}\text { Sitting meditation-30'; } \\
\text { Sharing the links between mood and thoughts; } \\
\text { Breath space-coping; }\end{array}$ & $\begin{array}{l}\text { Sitting meditation-30'; Sharing the links between } \\
\text { mood and thoughts; Breath space-coping; }\end{array}$ & \\
\hline 6 & Sitting meditation-40'; Reading poetry; & Sitting meditation-40'; Reading poetry; & \\
\hline 7 & Body scan; Recognizing relapse; Suggestions & $\begin{array}{l}\text { Breathing meditation; } \\
\text { Recognizing relapse; Suggestions }\end{array}$ & \\
\hline 8 & Summary; New start & Summary; New start & \\
\hline
\end{tabular}

Figure 1.

Contents of the three mindfulness training curriculums.

Table 1.

Descriptive statistics results of subjects.

\begin{tabular}{|c|c|c|c|c|c|c|c|}
\hline & $\mathrm{N}$ & Male & Female & $\begin{array}{c}\text { Average age } \\
\text { M (SD) }\end{array}$ & $\begin{array}{c}\text { Depression degree in } \\
\text { pretest } M(\mathrm{SD})\end{array}$ & $\begin{array}{l}\text { Average attendance } \\
\text { rate } M(S D)\end{array}$ & $\begin{array}{c}\text { Homework completion } \\
\text { status M (SD) }\end{array}$ \\
\hline 8-week complete group & 16 & 6 & 10 & $21.64(2.62)$ & $22.00(4.29)$ & $6.50(0.82)$ & $3.35(0.82)$ \\
\hline 8-week informal group & 19 & 8 & 11 & $21.44(1.63)$ & $21.42(5.46)$ & $6.58(0.90)$ & $3.58(0.87)$ \\
\hline 4-week group & 20 & 8 & 12 & $22.43(2.38)$ & $20.10(3.61)$ & $3.80(0.41)$ & $3.16(1.12)$ \\
\hline In total & 55 & 22 & 33 & $21.86(2.23)$ & $21.11(4.50)$ & & $3.36(0.95)$ \\
\hline
\end{tabular}


number of the three groups of subjects for final analysis is 55 .

\section{Subject Characteristics}

Among 55 subjects, there are 33 female subjects and 22 male subjects with average age of $21.9(\mathrm{SD}=2.23)$. The average depression score of subjects in the pretest is $21.11(\mathrm{SD}=4.50)$. According to standard for evaluation of Beck Depression Inventory, the subjects are basically in the in-between position of moderate depression and major depression. Refer to Table 2 for the results.

During the intervention, the first two groups attended the activity for 8 weeks, and the third group attended the activity for 4 weeks. In calculating the average time of each group of subjects to attend the activity, 8-week complete group attended the activity for 6.50 times on average, 8-week informal group attended the activity for 6.58 times on average and 4-week group attended the activity for 3.80 times on average.

For weekly homework, the subjects needed make a record according to required format, then the instructor and assistant graded it with 1 to 5 points according to the performance of the homework of subjects, the higher the grade was, the better the performance was. And the average grade evaluated by two evaluators would be taken as the score for the homework. After the group activity was over, we made a statistics of the completion status of homework, and calculated average score of each group. The average score for 8 -week complete group is 3.35 , the average score for 8-week informal group is 3.58 and the average score for 4-week is 3.16. Refer to Table 1.

\section{Outcome Analysis: The Differences among Three Group}

Use one-way ANOVA to compare the pretest scores of the three groups of subjects. The results show that, there is no obvious difference among the depression degrees of the three groups $(\mathrm{F}$ $(2,52)=0.86, p>0.01)$, there is no obvious difference in the scores of mindfulness $(\mathrm{F}(2,52)=0.30, p>0.01)$, and there is obvious difference in the scores for five items of mindfulness. Refer to Table 2 for the results.

Use one-way ANOVA to compare the posttest scores of the three groups of subjects. Results indicate that, the three groups show great difference in scores of the four items of depression $(\mathrm{F}(2,52)=0.01, p<0.05)$, total score of mindfulness (F (2,

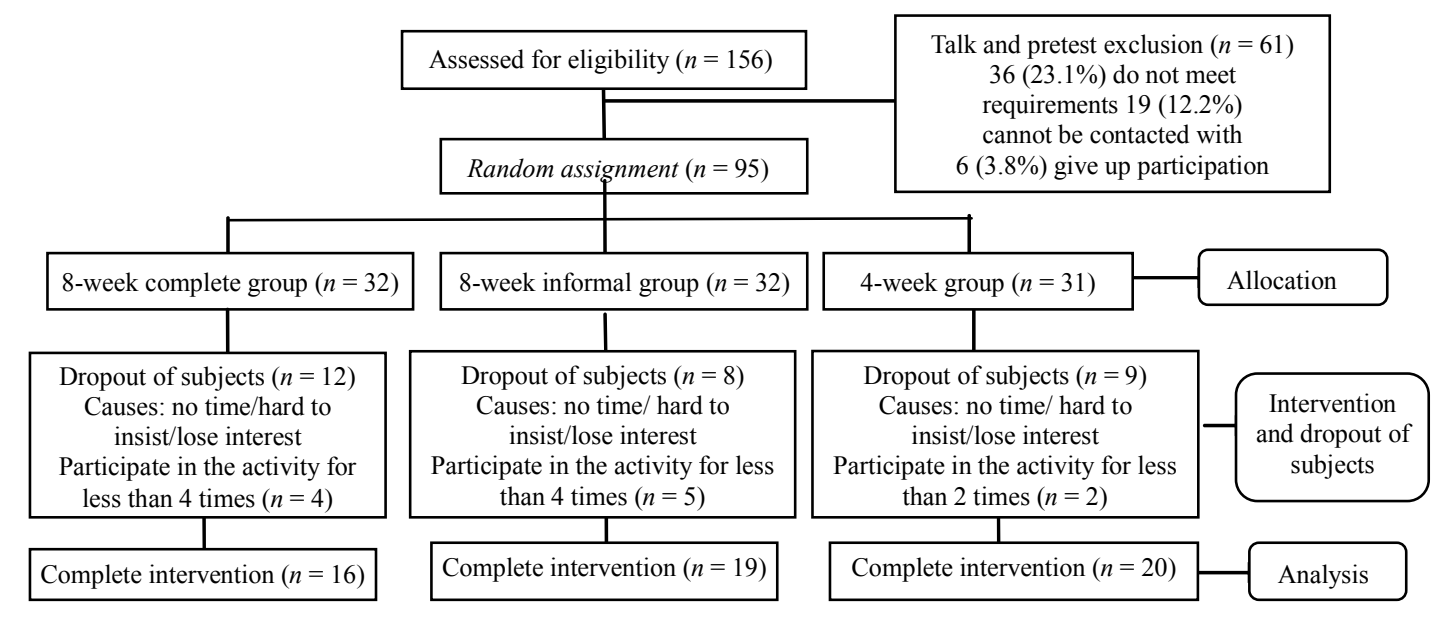

Figure 2.

The situations of the subjects during research process.

Table 2.

Comparison of pretest scores among the three groups the result of one-way ANOVA.

\begin{tabular}{|c|c|c|c|c|c|c|c|c|c|c|c|c|c|c|c|c|}
\hline & \multicolumn{8}{|c|}{ Pretest } & \multicolumn{8}{|c|}{ Protest } \\
\hline & \multicolumn{2}{|c|}{ Group 1} & \multicolumn{2}{|c|}{ Group 2} & \multicolumn{2}{|c|}{ Group 3} & \multirow[b]{2}{*}{$\mathrm{F}$} & \multirow[b]{2}{*}{ Sig. } & \multicolumn{2}{|c|}{ Group 1} & \multicolumn{2}{|c|}{ Group 2} & \multicolumn{2}{|c|}{ Group 3} & \multirow[b]{2}{*}{$\mathrm{F}$} & \multirow[b]{2}{*}{ Sig. } \\
\hline & M & SD & M & SD & M & SD & & & M & SD & M & SD & M & SD & & \\
\hline Depression & 22.00 & 4.29 & 21.42 & 5.46 & 20.10 & 3.61 & 0.86 & 0.43 & 5.81 & 4.69 & 4.95 & 2.86 & 10.60 & 7.76 & $5.75^{*}$ & 0.01 \\
\hline Mindfulness & 89.31 & 10.38 & 91.63 & 9.85 & 91.65 & 10.07 & 0.30 & 0.74 & 110.31 & 17.08 & 117.21 & 9.86 & 102.10 & 13.10 & $6.19^{*}$ & 0.00 \\
\hline Observe & 25.00 & 4.90 & 23.42 & 4.72 & 25.55 & 5.16 & 0.96 & 0.39 & 27.94 & 5.23 & 28.21 & 3.17 & 26.55 & 4.78 & 0.78 & 0.47 \\
\hline Describe & 18.94 & 3.96 & 21.84 & 6.21 & 20.05 & 3.86 & 1.63 & 0.21 & 23.06 & 4.14 & 25.89 & 3.51 & 22.10 & 4.68 & 4.34 & 0.02 \\
\hline $\begin{array}{l}\text { Act with } \\
\text { awareness }\end{array}$ & 12.56 & 4.95 & 15.68 & 3.46 & 13.70 & 5.22 & 2.09 & 0.13 & 18.81 & 5.43 & 22.68 & 4.20 & 16.85 & 5.36 & $6.77^{*}$ & 0.00 \\
\hline Nonjudge & 13.25 & 4.09 & 11.42 & 4.13 & 12.20 & 3.64 & 0.94 & 0.40 & 17.69 & 4.76 & 17.89 & 5.57 & 16.30 & 2.83 & 0.72 & 0.49 \\
\hline Nonreact & 19.56 & 3.35 & 19.26 & 4.47 & 20.15 & 3.33 & 0.28 & 0.76 & 22.81 & 3.39 & 22.53 & 3.96 & 20.30 & 3.56 & 2.67 & 0.08 \\
\hline
\end{tabular}

Note: ${ }^{*}$ The mean difference is significant at the 0.05 level. Group 1: 8-week complete group $(\mathrm{n}=16)$; Group 2: 8-week informal group ( $\left.\mathrm{n}=19\right)$; Group 3: 4-week group (n $=20)$. 
$52)=0.00, p<0.05)$, describe $(\mathrm{F}(2,52)=0.02, p<0.05)$, act with awareness $(\mathrm{F}(2,52)=0.00, p<0.05)$. The depression score of 4-week group is the highest among the three groups, whole the total score of mindfulness of 4-week group is the lowest among the three groups. Refer to Table 2 for results.

Use LSD post hoc suggestions to further compare posttest score difference of the three groups on the above 4 items. For the depression score, the score of 8 -week formal group is obviously lower than that of 4-week group, $p<0.01$; 8 -week complete group is obviously lower than 4 -week group, $p<0.05$. For total score of mindfulness, the score of 8-week informal group is obviously higher than that of 4 -week group, $p<0.01$. In the describe item, the score of 8 -week informal group is obviously than that of 8-week formal group and 4-week group, $p<0.05$. For the act with awareness, the score of 8 -week informal group is obviously higher than that of 8 -week complete group, $p<$ 0.05 ; the score of 8 -week informal group is obviously higher than that of 4-week group, $p<0.01$.

\section{Outcome Analysis: The Effect of the Intervention}

Use paired sample $\mathrm{T}$ test to respectively compare the differences of pretest and posttest scores of the three groups, and refer to Table 3 for results. Results show that, the average depression score of the three groups have obviously decreased $(\mathrm{t}$ $(15)=14.05, p<0.01 ; \mathrm{t}(18)=12.09, p<0.01 ; \mathrm{t}(19)=5.96, p$ $<0.01)$. It can been seen from Figure 3, the depression score of 8 -week complete group has dropped to 5.81 points in posttest score from 22 points in pretest score, with score decreasing rate of $73.6 \%$; the depression score of 8 -week informal group has dropped to 4.95 points in posttest score from 22.42 points in pretest score, with score decreasing rate of $76.9 \%$; the depression score of 4-week group has dropped to 10.60 points in posttest score from 20.10 points in pretest score, with score decreasing rate of $47.3 \%$. Refer to Figure 3 for results.

The total scores of mindfulness of the three groups have been obviously increased $(\mathrm{t}(15)=-4.68, p<0.01 ; \mathrm{t}(18)=-8.26, p$ $<0.01 ; \mathrm{t}(19)=-3.33, p<0.01)$. From the column chart of total score of mindfulness, the score of 8-week complete group has increased to 110.31 points in posttest from 89.31 points in pretest, with an score increasing rate of $19.03 \%$; the score of 8 -week informal group has increased to 117.21 points in the posttest from 91.63 points in the pretest, with score increasing rate of $21.82 \%$; the score of 4 -week group has increased to 102.10 points in posttest from 91.65 points in pretest, with score increasing rate of $10.23 \%$. Refer to Figure 4 for results.

However, the differences of the three groups in different items of the mindfulness are inconsistent. Among which, 8week complete group has obvious improvements after intervention in scores of all the five items of observe $(\mathrm{t}(15)=-2.46, p$ $<0.01)$, describe ( $\mathrm{t}(15)=-3.39, p<0.01)$, act with awareness $(\mathrm{t}(15)=-6.19, p<0.01)$, nonjudge $(\mathrm{t}(15)=-2.88, p<0.05)$ and nonreact $(\mathrm{t}(15)=-3.18, p<0.05)$. 8-week informal group also has obvious improvement in the scores of the five items,

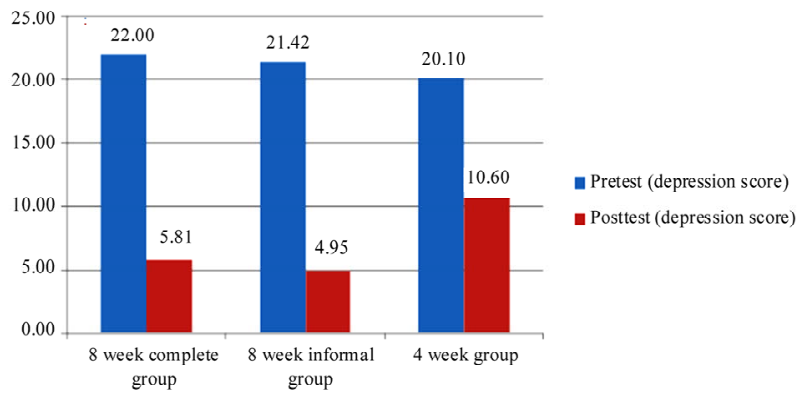

Figure 3.

Change of depression scores of the three groups before and after intervention.



Figure 4.

Change of total scores of mindfulness of the three groups before and after intervention.

Table 3.

$\mathrm{T}$ test results of pretest and posttest scores in different items.

\begin{tabular}{|c|c|c|c|c|c|c|c|c|c|c|c|c|c|c|c|}
\hline & \multicolumn{5}{|c|}{ 8-week complete group } & \multicolumn{5}{|c|}{ 8-week informal group } & \multicolumn{5}{|c|}{ 4-week group } \\
\hline & \multicolumn{2}{|c|}{ Pretest } & \multicolumn{2}{|c|}{ Posttest } & \multirow[b]{2}{*}{ t. } & \multicolumn{2}{|c|}{ Pretest } & \multicolumn{2}{|c|}{ Posttest } & \multirow[b]{2}{*}{ t. } & \multicolumn{2}{|c|}{ Pretest } & \multicolumn{2}{|c|}{ Posttest } & \multirow[b]{2}{*}{$\mathrm{t}$} \\
\hline & M & SD & M & SD & & M & SD & M & SD & & M & SD & M & SD & \\
\hline Depresson & 22 & 4.29 & 5.81 & 4.69 & $14.05^{* *}$ & 21.42 & 5.46 & 4.95 & 2.86 & $12.09^{* *}$ & 20.1 & 3.61 & 10.6 & 7.76 & $5.96^{* *}$ \\
\hline Mindfulness & 89.31 & 10.38 & 110.31 & 17.08 & $-4.68^{* *}$ & 91.63 & 9.85 & 117.2 & 9.86 & $-8.26^{* *}$ & 91.65 & 10.07 & 102.1 & 13.1 & $-3.33^{* *}$ \\
\hline Observe & 25 & 4.9 & 27.94 & 5.23 & $-2.46^{* *}$ & 23.42 & 4.72 & 28.21 & 3.17 & $-4.85^{* *}$ & 25.55 & 5.16 & 26.55 & 4.78 & $-0.87^{* *}$ \\
\hline Describe & 18.94 & 3.96 & 23.06 & 4.14 & $-3.39^{* *}$ & 21.84 & 6.21 & 25.89 & 3.51 & $-3.22^{* *}$ & 20.05 & 3.86 & 22.1 & 4.68 & $-2.26^{* *}$ \\
\hline Act with awareness & 12.56 & 4.95 & 18.81 & 5.43 & $-6.19^{* *}$ & 15.68 & 3.46 & 22.68 & 4.2 & $-7.74^{* *}$ & 13.7 & 5.22 & 16.85 & 5.36 & $-4.01^{* *}$ \\
\hline Nonjudge & 13.25 & 4.09 & 17.69 & 4.76 & $-2.88^{*}$ & 11.42 & 4.13 & 17.89 & 5.57 & $-5.51^{* *}$ & 12.2 & 3.64 & 16.3 & 2.83 & $-4.05^{* *}$ \\
\hline Nonreact & 19.56 & 3.35 & 22.81 & 3.39 & $-3.17^{*}$ & 19.26 & 4.47 & 22.53 & 3.96 & $-3.70^{* *}$ & 20.15 & 3.33 & 20.3 & 3.56 & $-0.19^{* *}$ \\
\hline
\end{tabular}

Note: ${ }^{*}$ The mean difference is significant at the 0.05 level. ${ }^{* *}$ The mean difference is significant at the 0.01 level. 
with $(\mathrm{t}(18)=-4.85, p<0.01 ; \mathrm{t}(18)=-3.22, p<0.01 ; \mathrm{t}(18)=$ $-7.74, p<0.01 ; \mathrm{t}(18)=-5.51, p<0.01 ; \mathrm{t}(18)=-3.70, p<$ $0.01)$. While 4 -week group only has obvious improvement in the scores of the three items of describe $(\mathrm{t}(19)=-2.26, p<$ $0.05)$, act with awareness ( $\mathrm{t}(19)=-4.01, p<0.01)$ and nonjudge ( $\mathrm{t}(19)=-4.05, p<0.01)$, but the 4-week group has no obvious improvement in score of the two items of observe $(\mathrm{t}$ $(19)=-0.87, p>0.05)$ and nonreact $(\mathrm{t}(19)=-0.19, p>0.05)$.

\section{Discussion}

\section{The Intervention Effects on Depression}

Though the time and contents arrangement of the three mindfulness trainings in the research are different, they have obviously reduce the depression degrees of the subjects, which can be seen from data in Table $\mathbf{3}$ and Figure 3. The decrease of depression scores verifies the effectiveness of mindfulness training in the research on one hand, and it also verifies the research conclusions of using mindfulness cognitive therapy to intervene depressed patients before on the other hand.

To specifically compare the differences among the three groups, the score decrease rate of the 4-week group on depression score $(47.3 \%)$ is the least in comparison with 8-week complete group (73.6\%) and 8-week informal group (76.9\%) (Figure 3), and although 4-week group also has obvious intervention effects, it still lacks behind 8-week complete group and 8 -week informal group $(p<0.05)$. In the mindfulness cognitive therapy, mindfulness training helps the subjects to know the relationship between their own thoughts and emotions, and helps subjects to objectively observe and regard their own thoughts from another point of view. The practice time for both 8 -week complete group and 8-week informal group is 8 weeks while the practice time for 4-week group is 4 weeks, which indicates that the practice time plays an important role in mindfulness cognitive therapy. Although short-time mindfulness training can reduce the depression level, but its effect is not so obvious as long-time mindfulness training. In mindfulness training, the subjects need to learn to observe themselves from another perspective without falling into automatic thoughts. Such transformation of thinking habit needs a certain period of practicing time as foundation indeed.

Meanwhile, the difference between 8-week complete group and 8 -week informal group is not obvious $(p>0.05)$, which reminds researchers that for the intervention of mindfulness training on depression, body scanning may not be necessary. The body scanning practice focuses on training the awareness on body parts, but the depressed individuals generally are very sensitive to the awareness of their own state. In 8-week informal group, the subjects do not practice body scanning, but they practice using mindfulness in daily life, such as mindfulness walking, mindfulness working and so on, and the depression degree of subjects in 8-week informal group has also been obviously reduced, so it can been seen that informal mindfulness practice may replace body scanning practice in 8 -week formal mindfulness practice. This provides a very good training mode for individuals who do not have time or have no ability to practice formal mindfulness training, which will enable them to know mindfulness thought in daily life and use it in their life, so that they can effectively adjust their emotional state.

In the variance of scores in mindfulness scale (see Table 3), the results show that, the subjects in the three groups all have obvious improvement only in the posttest score of nonjudge item, and there is no difference among the three groups (see Table 2), while the three groups have some difference in the other 4 items in some aspects. The results show that, the key for mindfulness cognitive therapy to treat depression symptoms is to train and cultivate "nonjudge" thinking mode of the subjects, while other training modes such as the training of body scanning on awareness might only assist in treating depression. Of course, the difference may also be caused by the difference among the subjects of the groups, and more research is needed to come into definite conclusions.

\section{The Effects of Training Time on Mindfulness Level}

From the perspective of training time, the research can be divided into two training modes, one of which is 8-week mindfulness training (8-week complete group and 8-week informal group), and the other of which is 4 -week mindfulness training (4-week group). The difference between 8 -week mindfulness training and 4-week mindful training lies in that, in 8-week group, subjects need to participate in group activity for 8 times and need to complete 8 -week homework, that is, the subjects' learning time in the group and practice time after class of 8week group is twice of that of 4-week group. The research also finds that, different training modes have different effects on five items of mindfulness. After 8-week mindfulness training in 8 -week complete group and 8-week informal group, the subjects have obvious improvement on the scores of five items of mindfulness (Table 3). After 4-week mindfulness training in the 4-week group, scores of 3 items out of the 5 items have been obviously improved, while the scores of observe item $(\mathrm{t}(19)=$ $-0.87, p>0.05)$ and nonreact item (t $(19)=-0.19, p>0.05)$ improve to a certain extent after intervention, but they have no obvious improvement (see Table 3). In some extent, the effect of duration on the intervention can be explained by the two reasons.

First, the establishment of new thinking mode "being" needs to conquer the original response mode "doing", which is the most difficult to conquer in all practices, and the main way to solve it is by large quantity of practice. However, due to time constraints, practice times were greatly reduced, and this is adverse to establish a new thinking mode.

The 4-week group began to practice meditation in the third week, which would be practiced once in the group and would be practiced for two weeks after training with 14 practice times in total. While the 8-week complete group and 8-week informal group began to practice meditation in the fifth week, which would be practiced once each for 15 minutes, 30 minutes and 40 minutes, and which would be practiced for 4 weeks after training, with 28 practice times in total. So, the insufficiency of practice times might be the main reason for the unobvious improvement on the two items of observe and non-react in 4-week group.

Second, as the hurried practice, subjects more easily took mindfulness practice as coping strategies for dealing with bad emotions, while they used less time and energy to explore the deep meaning of mindfulness. This caused subjects usually encountered more obstacles in the practice, and it might impair the subjects' enthusiasm for keeping practice. For example, in the sharing stage of the third group activity, group member No. 307 came up with that, the activity progressed too fast, especially that the breathing space practice was difficult to command in one time; group member No. 319 pointed out that he 
couldn't distinguish the difference between body scanning and meditation, both of which seemed to pay attention to body's feelings; Besides, many group members asked the significance of the practice which focused on observation without response. For subjects of 8-week complete group and 8-week informal group, they only come into contact with one to two new activities each time with slower course rhythm and sufficient practice time after class. Compared with 4 -week group, these subjects have mastered each practice better, have deeper understanding of mindfulness, and in the latter half period of the course, most group members are willing to share their understanding in the mindfulness training instead of asking the purpose and significance of the practice.

\section{The Effects of Training Contents on Mindfulness Level}

The three groups have different contents arrangement in mindfulness training, both 8-week complete group and 4-week group practice all mindfulness contents, while 8-week informal group does not practice body scanning and it focuses on practice mindfulness in daily life; Besides, 4-week group only practices each item for once during the activity, while 8-week complete group practices each item at least twice during the activity. The mindfulness levels of the three groups are all improved obviously, but the difference of training contents affects the scores of mindfulness items in various degrees.

For the item of act with awareness, there is no obvious difference among the pretest scores of the three groups, but there is obvious difference among the posttest scores of the three groups $(\mathrm{F}(2,52)=6.77, p<0.01$ see Table 2$)$. 8-week informal group improves the most in posttest scores, and the difference among posttest scores of 8-week informal group, 8-week complete group and 4-week group is obvious. Therefore, we pay attention to particular characteristics of the training in 8week informal group. As informal training group, 8-week informal group lay stress on practicing mindfulness in daily life by informal training mode, such as brushing teeth with awareness, having meals with awareness, walking with awareness and washing clothes with awareness, so as to cultivate awareness towards life. When the subjects of 8 -week complete group and 4-week group finish their homework of body scanning in the first two weeks, 8-week informal group has begun to try using mindfulness in life, which is exactly the training directed towards act with awareness. Researchers consider that, the uniqueness in training contents is the main factor that causes the obvious difference between 8-week informal group and 8-week complete group as well as 4-week group in the item of act with awareness.

In addition, 8-week informal group does not practice body scanning that is formal practice and takes longer time, which also brings one corresponding advantage that subjects of 8 week informal group has more sufficient time in other activities in the group and the discussion and sharing between members are more sufficient. The effects that the difference brings are reflected in that, there is obvious difference between the describe item of 8-week informal group and that of 8-week complete group and 4-week group, and the score of describe item of 8 -week informal group with sufficient group discussion time is obviously higher than that of 4-week group with compact contents arrangement and less discussion time $(p<0.05)$. The describe item lies in whether the group members are able to clearly express their thoughts and feelings, the improvement of which is inseparable from mindfulness training on the subjects' awareness and perception as well as group sharing and discussion. Especially for depressed individuals, this is particularly obvious.

The main form of mindfulness training is group activity, which is similar to group counseling, so the group dynamics will have effects on subjects in no doubt. The mindfulness group in the research is composed of depressed university students. The depressed individuals generally have very fixed thinking model, and their description is monotonous and appraisive, and they will frequently associate with their drawback and shortcomings and thus have the thought of helplessness and desperation (such as Bjarehed, Sarkohi, \& Andersson, 2010). Negative thinking mode will repeat again and again and will seriously affect the emotions and life of de-pressed patients. However, in group sharing, these university students with strong learning ability and introspection ability will hear different opinions and different experience from others and learn other information that is different from their own. For example, in the sharing period after walking meditation, under the encouragement and guidance of the instructor, different subjects share their different experience: some feel swaying of their legs, some have the feelings that are close to cramps, some find that they are luckier than the disabled, and some think of their hurried walking appearance in normal times. Group discussion will change their original fixed and rigid thinking mode, and after subjects receive and reflect upon these differences, their thinking will thus be more broad and flexible, which is the effects of mindfulness training or a key factor of treating the depressed patients. What is more important, these changes are perceived by the subjects from other subjects and are not from the stereotype indoctrination of the instructor, which is good for the maintenance of the changes.

\section{In Group Activity Design, the Relation between Subjects Dropout Rate, Subjects Attendance Rate, Homework Completion Status and Intervention Effects}

The research also makes statistics of subjects' attendance of group activity and assignment completion situation each week. The results show that, the average attendance rates of the three groups are 6.50 times, 6.58 times and 3.80 times respectively (see Table 1). The subjects in 4-week group almost attend all the four group activities with the highest attendance rate among the three groups. However, the statistical analysis excludes 4 subjects with lower attendance times in the groups, so the results may not be very accurate. However, combined with the subjects dropout rate in the three groups $(50 \%, 40.6 \%$ and $37.5 \%$ ) and the subjective perception of the instructor, the 4-week group activity design is better for the subjects to attend group activities, better for the subjects to properly learn all contents of mindfulness training in group activity, and better for ensuring the completeness of the group dynamics.

When the activity is designed to be 8 weeks, because the overall training time is too long, the subjects are easily to get weary and may fail to attend the activities due to temporary emergency in the medium term. For example, some subject left the group because he needed to go out for a period of time in 8 -week informal group, and in 8-week complete group, some subject failed to attend the group activity twice in succession. 
Absence from group activities, especially absence from the activities twice in succession, will seriously affect consistency of practice. When subjects participate in the activities again, it is difficult for them to make up the missing parts, it will hinder learning and understanding the subsequent learning contents, and will further affect the overall intervention effects of mindfulness training.

Besides attending group activity, subjects' homework completion status also has important effects on intervention results. Compared with the homework completion status, the results show that homework completion status in 4-week group is the worst $(\mathrm{M}=3.16, \mathrm{SD}=1.62)$, and homework completion status in 8-week informal group is the best among the three groups (M $=3.58, \mathrm{SD}=0.87)$. The difference of homework completion status is also reflected in the difference of contents arrangement and homework arrangement: 4-week group has more course contents arranged and has more homework, and large amount of homework and insufficient course practice affects the homework completion status of subjects. For homework of 8-week informal group, there is no practice for body scanning and there is more informal practice which is easier to be operated, so the homework completion quality of 8-week informal group is guaranteed. This is one of the reasons for different intervention effects of the three groups.

\section{Conclusions and Prospects}

All the three different mindfulness training modes in the research have obvious intervention effects on depression, and the intervention effects of 8-week training are better than those of 4-week training. Different mindfulness training modes will have significant impact on the improvement of mindfulness level, for instance, informal training mode is good for enhancing the item of "act with awareness", compared with short-term training mode, long-term training mode is better in improving the two items "observe" and "nonreact", and sufficient discussion and practice within the group is good for improving the "describe" item of the subjects. Meanwhile, different group activity design is relevant to subject dropout rate, attendance rate, homework completion status and intervention effects.

This study is beneficial for seeking the optimized mindfulness training mode (which is time saving, easy and effective). And it may perfect the operation standard of mindfulness training, especially for the non-clinical groups. At present, many reports in this field are still about completing mindfulness training modes, so it needs further research on the comparison between the formal training and informal training. This study also helps to distinguish the mechanism of the specific training content, thus it will help the mentor guide more accurately and specifically. For example, "body scan" may be guided with the purpose of "observation" and "nonreact". Future research can be combined with cognitive neuroscience method to determine the mechanism, and measure the effect with some fixed intervention point.

Subject dropout is one of the limitations in this study. As we think, here may be two following reasons: firstly, the subjects are university students whose depressed symptoms are not as serious as the clinical patients, secondly, this intervention didn't submit any money or give credits to these subjects. So their motivation might be lower than the clinical groups, which might give rise to the number of subject dropout. The high dropout rate might suggest the mindfulness training was not as valid as the study argued. In future studies, psychotherapists should consider some better ways to solve this problem. In addition, the depression was only measured in a single way. Beck Depression Inventory-II is a self-report inventory, like all questionnaires, the scores can be easily exaggerated or minimized by the subjects. And it cannot be used in clinical diagnosis. If the study could use the modes with other measurement tools and analysis combining multiple scale data, such as HAMD and SDS, the results would be more persuasive.

\section{REFERENCES}

Alberts, H. J. E. M., \& Thewissen, R. (2011). The effect of a brief mindfulness intervention on memory for positively and negatively valenced stimuli. Mindfulness, 2, 73-77. doi: 10.1007/s12671-011-0044-7

Anna, M. T., Yvonne, M. C., \& Catherine, R. (2004). Mindfulnessbased stress reduction in women with breast cancer. Families, Systems \& Health, 22, 193-203. doi:10.1037/1091-7527.22.2.193

Baer, R. A. (2006). Mindfulness training as a clinical intervention: A conceptual and empirical review. Clinical Psychology: Science and Practice, 10, 125-143. doi:10.1093/clipsy.bpg015

Biegel, G. M., Brown, K. W., Shapiro, S. L., \& Schubert, C. M. (2009). Mindfulness-based stress reduction for the treatment of adolescent psychiatric outpatients: A randomized clinical trial. Journal of Consulting and Clinical Psychology, 77, 855-866. doi:10.1037/a0016241

Bjarehed, J., Sarkohi, A., \& Andersson, G. (2010). Less positive or more negative? Future-directed thinking in mild to moderate depresssion. Cognitive Behaviour Therapy, 39, 37-45. doi:10.1080/16506070902966926

Brotto, L. A., Seal, B. N., \& Rellini, A. (2012). Pilot study of a brief cognitive behavioral versus mindful-ness-based intervention for women with sexual distress and a history of childhood sexual abuse. Journal of Sex \& Marital Therapy, 38, 1-27. doi:10.1080/0092623X.2011.569636

Byrne, B. M., Stewart, S. M., \& Lee, P. W. H.(2004).Validating the beck depression inventory-II for Hong Kong Community Adolescents. International Journal of Testing, 4, 199-216. doi:10.1207/s15327574ijt0403 1

Chambers, R., Lo, B. C., Yee, \& Allen, N. B. (2008). The impact of intensive mindfulness training on attentional control, cognitive style, and affect. Cognitive Therapy and Research, 32, 303-322. doi:10.1007/s10608-007-9119-0

Daubenmier, J., Kristeller, J., Hecht, F. M., Maninger, N., Kuwata, M., Jhaveri, K. et al. (2011). Mindfulness intervention for stress eating to reduce cortisol and abdominal fat among overweight and obese women: An exploratory randomized controlled study. Journal of Obesity, 6, 19-36.

Deng, Y. Q. (2009). Effects of mindfulness on the mental health level in the university students. Thesis, Beijing: Capital Normal University.

Deng, Y. Q., Liu, X. H., Rodriguez, M. A., \& Xia, C.-Y. (2011). The five facet mindfulness questionnaire: Psychometric properties of the Chinese version. Mindfulness, 2, 123-128. doi:10.1007/s12671-011-0050-9

Hoelzel, B. K., Carmody, J., Evans, K. C., Hoge, E. A., Dusek, J. A., Morgan, L. et al. (2010). Stress reduction correlates with structural changes in the amygdala. Social Cognitive and Affective Neuroscience, 5, 11-17. doi:10.1093/scan/nsp034

Joanne, C. K., Susan, D., Wiley, T. C., Debra, M. B., \& Shauna, S. (2004). The effects of mindfulness-based stress reduction on nurse stress and burnout-A quantitative and qualitative study. Holistic Nursing Practice, 18, 302-308.

Joanne, C. K., Susan, D., Wiley, T. C., Debra, M. B., \& Shauna, S. (2005a). The effects of mindfulness-based stress reduction on nurse stress and burnout-A quantitative and qualitative study, part II. Holistic Nursing Practice, 19, 26-35.

Joanne, C. K., Susan, D., Wiley, T. C., Debra, M. B., \& Shauna, S. (2005b). The effects of mindfulness-based stress reduction on nurse 
stress and burnout-A quantitative and qualitative study, part III. Holistic Nursing Practice, 19, 78-86.

Kabat-Zinn, J. (1994). Wherever you go, there you are: Mindfulness meditation in everyday life. New York: Hyperion

Lutz, A., Slagter, H. A., Dunne, J. D., \& Davidson, R. J. (2008). Attention regulation and monitoring in meditation. Trends in Cognitive Sciences, 12, 163-169. doi:10.1016/j.tics.2008.01.005

Marchand, W. R. (2012). Self-referential thinking, suicide, and function of the cortical midline structures and striatum in mood disorders: Possible implications for treatment studies of mindfulness-based interventions for bipolar depression. Depression Research and Treatment, 2, 1-16. doi:10.1155/2012/246725

Ma, S. H., \& Teasdale, J. D. (2004). Mindfulness-based cognitive therapy for depression: Replication and exploration of differential relapse prevention effects. Journal of Consulting and Clinical Psychology, 72, 31-40. doi:10.1037/0022-006X.72.1.31

Ortner, C. N. M., Kilner, S. J., \& Zelazo, P. D. (2007). Mindfulness meditation and reduced emotional interference on a cognitive task. Motivation and Emotion, 31, 271-283. doi:10.1007/s11031-007-9076-7

Rood, L., Roelofs, J., Bogels, S. M., \& Alloy, L. B. (2010). Dimensions of negative thinking and the relations with symptoms of depression and anxiety in children and adolescents. Cognitive Therapy and Research, 34, 333-342. doi:10.1007/s10608-009-9261-y

Semple, R. J. (2010). Does mindfulness meditation enhance attention? A randomized controlled trial. Mindfulness, 1, 121-130. doi:10.1007/s12671-010-0017-2

Shaw, S. (2006). Buddhist meditation: An anthology of texts from the Pāli Canon. London and New York: Routledge, 17, 76.

Shi, Z. Y. (2011). Effects of mindfulness training on the anxiety in university students. Science of Social Psychology, 26, 211-213.

Tang, Y. Y., Ma, Y. H., Wang, J. H., Fan, Y. X. et al. (2007). Shortterm meditation training improves attention and self-regulation. Proceedings of the National Academy of Sciences, 104, 17152-17156. doi:10.1073/pnas.0707678104

Teasdale, J. D., Segal, Z. V., Williams, J. M. G., Ridgeway, V. A., Soulsby, J. M., \& Lau, M. A. (2000). Prevention of relapse/recur- rence in major depression by mindfulness-based cognitive therapy. Journal of Consulting and Clinical Psychology, 68, 615-623. doi:10.1037/0022-006X.68.4.615

Tan, J. W., \& Wu, H. M. (2009). Mindfulness training in psychological counseling and psychotherapy. Journal of Mudanjiang College of Education, 94-95.

Wang, Z., Yuan, C. M., Huang, J., Li, Z. Z., Chen, J., Zhang, H. Y., Fang, Y. R., \& Xiao, Z. P.(2011). Reliability and validity of the Chinese version of Beck Depression Inventory-II among depression patients. Chinese Mental Health Journal, 25, 476-480.

Williams, J. M., Danielle S. D., Catherine C., Melanie J. V., \& Fennell (2006). Mindfulness-based cognitive therapy for prevention of recurrence of suicidal behavior. Journal of Clinical Psychology, 62, 201-210. doi:10.1002/jclp.20223

Williams, J. M. (2008). Mindfulness, depression and modes of mind. Cognitive Therapy and Research, 32, 721-733. doi:10.1007/s10608-008-9204-Z

Zangi, H. A., Mowinckel, P., Finset, A., Eriksson, L. R., Hoystad, T. O., Lunde, A. K. et al. (2012). A mindful-ness-based group intervention to reduce psychological distress and fatigue in patients with inflammatory rheumatic joint diseases: A randomised controlled trial. Annals of the Rheumatic Diseases, 71, 911-917. doi:10.1136/annrheumdis-2011-200351

Zautra, A. J., Davis, M. C., Reich, J. W., Nicassario, P., Tennen, H., Finan, P. et al. (2008). Comparison of cogni-tive behavioral and mindfulness meditation interventions on adaptation to rheumatoid arthritis for patients with and without history of recurrent depression. Journal of Consulting and Clinical Psychology, 76, 408-421. doi:10.1037/0022-006X.76.3.408

Zeidan, F., Johnson, S. K., Diamond, B. J., David, Z., \& Goolkasian, P. (2010). Mindfulness meditation improves cognition: Evidence of brief mental training. Consciousness and Cognition: An International Journal, 19, 597-605. doi:10.1016/j.concog.2010.03.014

Zindel, V. S, Williams, J. M. G., \& Teasdale, J. D. (2008). Mindfulness-based cognitive therapy for depression. New York: The Guilford Publications, 120-125. 